\title{
A numerical modeling study of the East Australian Current encircling and overwashing a warm-core eddy
}

\author{
H. S. Macdonald, ${ }^{1,5}$ M. Roughan, ${ }^{1,2}$ M. E. Baird, ${ }^{3}$ and J. Wilkin ${ }^{4}$ \\ Received 30 July 2012; revised 13 November 2012; accepted 18 November 2012; published 30 January 2013.
}

[1] Warm-core eddies (WCEs) often form in the meanders of Western Boundary Currents (WBCs). WCEs are frequently overwashed with less dense waters sourced from the WBC. We use the Regional Ocean Modelling System to investigate the ocean state during the overwashing of one such WCE in October 2008 in the East Australian Current (EAC). Comparisons of model outputs with satellite sea surface temperature and vertical profiles show that the model provides a realistic simulation of the eddy during the period when the EAC encircled and then overwashed the eddy. During the encircling stage, an eddy with closed circulation persisted at depth. In the surface EAC water entered from the north, encircled the eddy and exited to the east. The overwashing stage was initiated by the expulsion of cyclonic vorticity. For the following 8 days after the expulsion, waters from the EAC washed over the top of the eddy, transferring heat and anticyclonic vorticity radially-inward. After approximately one rotation period of overwashing, the eddy separated. The overwashing creates a two-layer system that forms a subsurface maximum velocity at the interface of the two layers. Analysis of water mass properties, Eulerian tracer dynamics, and Lagrangian particle tracks show that the original eddy sinks $10-50 \mathrm{~m}$ during the overwashing period. Overwashing has been observed in many WBCs and occurs in most WCEs in the western Tasman Sea.

Citation: Macdonald, H. S., M. Roughan, M. E. Baird, and J. Wilkin (2013), A numerical modeling study of the East Australian Current encircling and overwashing a warm-core eddy, J. Geophys. Res. Oceans, 118, 301-315, doi:10.1029/2012JC008386.

\section{Introduction}

[2] Mesoscale eddies are a ubiquitous feature of vigorous western boundary currents [Parker, 1971; Yang et al., 1999; Everett et al., 2012]. These eddies can have azimuthal velocities reaching speeds greater than $1 \mathrm{~m} \mathrm{~s}^{-1}$, diameters of the order of $200 \mathrm{~km}$, and have been investigated in each of the major western boundary currents (the East Australian Current, EAC, [Hamon, 1965], the Gulf Stream [Rossby, 1987; Oort, 1964], the Agulhas Current [Duncan, 1968], the Kuroshio [Yaochu and Jilan, 1988], and the Brazil Current [Didden and Schott, 1993]). Mesoscale eddies typically form in the unstable flow near the western boundary current's retroflection area.

[3] Warm-core (anticyclonic) eddies within western boundary systems can sink under a layer of even warmer water sourced from the Western Boundary Current (WBC),

\footnotetext{
${ }^{1}$ Coastal and Regional Oceanography Lab, School of Mathematics and Statistics, University of New South Wales, Sydney, Australia.

${ }^{2}$ Sydney Institute of Marine Science, Mosman, Australia.

${ }^{3}$ Climate Change Cluster, University of Technology Sydney, Sydney, Australia.

${ }^{4}$ Rutgers, The State University of New Jersey, USA.

${ }^{5}$ Now at School of Environmental Systems Engineering, University of Western Australia, Crawley, Australia.

Corresponding author: H. S. Macdonald, School of Environmental Systems Engineering, University of Western Australia, Crawley, Western Australia, Australia. (helen.macdonald@uwa.edu.au)

(C)2012. American Geophysical Union. All Rights Reserved. 2169-9275/13/2012JC008386
}

another warm-core eddy (WCE) or surrounding waters after cooling [Nof and Dewar, 1994; Baird et al., 2010; Tranter et al., 1982]. The resultant eddy has two distinct layers: a thin surface layer and a lower submerged layer. This process has also been referred to as flooding (in the EAC [Tranter et al., 1982]), submergence (in the EAC [Jeffrey and Hallegraeff, 1987]), and overwashing (in the North Atlantic [Chapman and Nof, 1988]) and has been observed in many different boundary currents (the Gulf Stream [Hitchcock et al., 1985]; the East Australian Current [Jeffrey and Hallegraeff, 1987], and the Leeuwin Current [Dietze et al., 2009]). In this paper we refer to the process as overwashing resulting in submergence (after Chapman and Nof [1988]).

\subsection{Warm-Core Eddies in the East Australian Current}

[4] The East Australian Current is a western boundary current that forms large WCEs, located on the east coast of Australia. The EAC bifurcates between $30-34^{\circ} \mathrm{S}$ [Godfrey et al., 1980] and part of it travels east to form the East Auckland Current while a current of diminishing strength can be observed travelling poleward along the Australian continental shelf until Tasmania $\left(42^{\circ} \mathrm{S}\right)$. The area of bifurcation is known as the EAC separation zone and is an energetic area with a large eddy variability [Ridgway and Godfrey, 1997]. The variability is created by eddies that are shed from the EAC at an interval of 90-180 days [Bowen et al., 2005; Mata et al., 2006]. In this region it has been shown that anticyclonic eddies, which favor downwelling and low productivity can, after overwashing, produce a subsurface 
chlorophyll maximum [Baird et al., 2010]. One such example of this is a WCE that started to form from an EAC meander in January of 2008 [Baird et al., 2010]. In October 2008 the EAC overwashed (referred to as flooded in [Baird et al., 2010]) over the surface of the eddy, submerging the original surface layer, creating a two-layer system.

\subsection{Warm-Core Eddies, Vertical Mixing, and Productivity}

[5] In two-layered eddy systems the fate of the water in the subsurface layer depends on the process leading up to this layering. In the numerical modeling study of Chapman and Nof [1988], a cooling is applied to the surface of the eddy, allowing it to sink below the surrounding water. In Tranter et al. [1980], a surface heating creates a surface cap to the eddy and the lower layer does not change its position vertically. In Baird et al. [2010], the process is different again because the surface layer comes from a lateral movement of EAC waters where the original eddy sank and water was then expelled from the eddy at depth and moved up the sides.

[6] An unanswered question pertains to the timing of overwashing, i.e., what determines when an eddy will be overwashed. In the experiments of Chapman and Nof [1988], the eddy completely sinks in a matter of weeks after a buoyancy difference between the eddy and surrounding waters is established. In the observations of a WCE in the EAC, Baird et al. [2010] found that the overwashing process did not even start until a couple of months after the eddy formed. Why this overwashing was delayed has not been examined.

[7] Warm-core eddies are also interesting from a biological productivity perspective. WCEs are conceptually considered to be nutrient deplete with significantly lower productivity than cold-core eddies [Bakun, 2006]. Hence, the vertical mixing processes, which have the potential to supply nutrients and seed populations, are of critical significance for the production of algal blooms in WCEs [Kahru et al., 2007; McGillicuddy et al., 2007]. In addition to the above physical questions, quantifying the vertical structure and resultant mixing processes combined with determining the source of waters entrained into WCEs will lead to a better understanding of algal blooms, production rates, and species composition within the eddy.

[8] Other uplift processes have been identified in WCEs. These include, the velocity shear between the swiftly moving eddy and the relatively still surrounding ocean [Capet et al., 2008], the frictional decay of the eddy [Nelson et al., 1989; Flierl and Mied, 1985], the coalescence of WCEs [Cresswell, 1983], a deepening of the mixed layer [Tranter et al., 1980], and the separation of a WCE from the continental shelf [Nilsson and Cresswell, 1980].

[9] As well as nutrient availability, a further limitation on biological growth in a WCE is light availability. Depthintegrated light can be low in the deep surface mixed layer of a WCE, which results in light-limited phytoplankton growth. Light-limitation can be overcome by overwashing, which causes stratification, thus decreasing the depth of the surface mixed layer. This allows for growth in the new, shallower, light-filled surface mixed layer. This process was identified by Baird et al. [2010] and Tranter et al. [1980], where a nutrient poor, but optically clear layer of water flooded over the top of a WCE, resulting in an algal bloom in the pycnocline.

[10] Investigations of the vertical structure within eddies have to date been limited to sporadic and coarse resolution observations (e.g., from shipboard conductivity-temperaturedepth (CTD) casts or Argo float profiles and more recently autonomous glider observations). Hence, we are motivated to create a realistic model of surface overwashing in a WCE to better understand vertical movement, the timing of the event and thus understand entrainment and possible increased productivity. The model provides much greater spatial and temporal resolution to the observation of Baird et al. [2010] and allows for tracer and particle tracking. In particular, we investigate conservation of vorticity, heat, and energy in the eddy and how these properties are transferred from the EAC to the eddy.

[11] In this paper, the Regional Ocean Modelling System (described in section 2) is used to investigate the spatial and temporal evolution (formation and shedding) of an overwashing WBC eddy that formed in October 2008 in the EAC. The model reveals significant insights into the vertical structure and mixing processes within the eddy as well as the transfer of vorticity from the EAC to the eddy (section 3). We describe in detail the subsurface properties (temperature, salinity, and velocity) and most importantly we identify the source waters and the vertical and horizontal movement within and across the boundary of the eddy. The results are then discussed (section 4) in the context of vorticity and buoyancy, providing new insights into the overwashing process.

\section{Methods}

\subsection{Model Description}

[12] The ocean state of the October 2008 WCE is simulated using the Regional Ocean Modelling system (ROMS). ROMS solves the primitive nonlinear, Boussinesq and hydrostatic equations allowing for a free surface on a curvilinear, terrain-following grid [Shchepetkin and McWilliams, 2003; Shchepetkin and McWilliams, 2005]. The ROMS kernel is designed to reduce the pressure gradient truncation errors associated with this terrain following scheme [Shchepetkin and McWilliams, 2003].

[13] For more details on ROMS the reader is referred to Shchepetkin and McWilliams [2003] and Shchepetkin and McWilliams [2005].

[14] In the configuration used here, the baroclinic time step is $120 \mathrm{~s}$ and there are 60 barotropic time steps to each baroclinic step. The Mellor and Yamada [1982] 2.5 turbulent closure scheme is used in parameterizing vertical mixing.

\subsubsection{Initial, Boundary, and Climatology Data}

[15] SynTS is a daily, three-dimensional (3D) temperature and salinity estimate produced by the Commonwealth Scientific and Industrial Research Organisation, which is based on available satellite sea surface temperature (SST) and vertical profiles (Argo floats) [Ridgway et al., 2008]. SynTS has a $10 \mathrm{~km}$ resolution and uses multiple linear regression methods to estimate the ocean state. Geostrophic currents are calculated from this temperature and salinity field using a reference depth of $2000 \mathrm{~m}$. SynTS products (temperature, salinity, and geostrophic currents) are used in this configuration for model initialization and time-varying boundary forcing. 

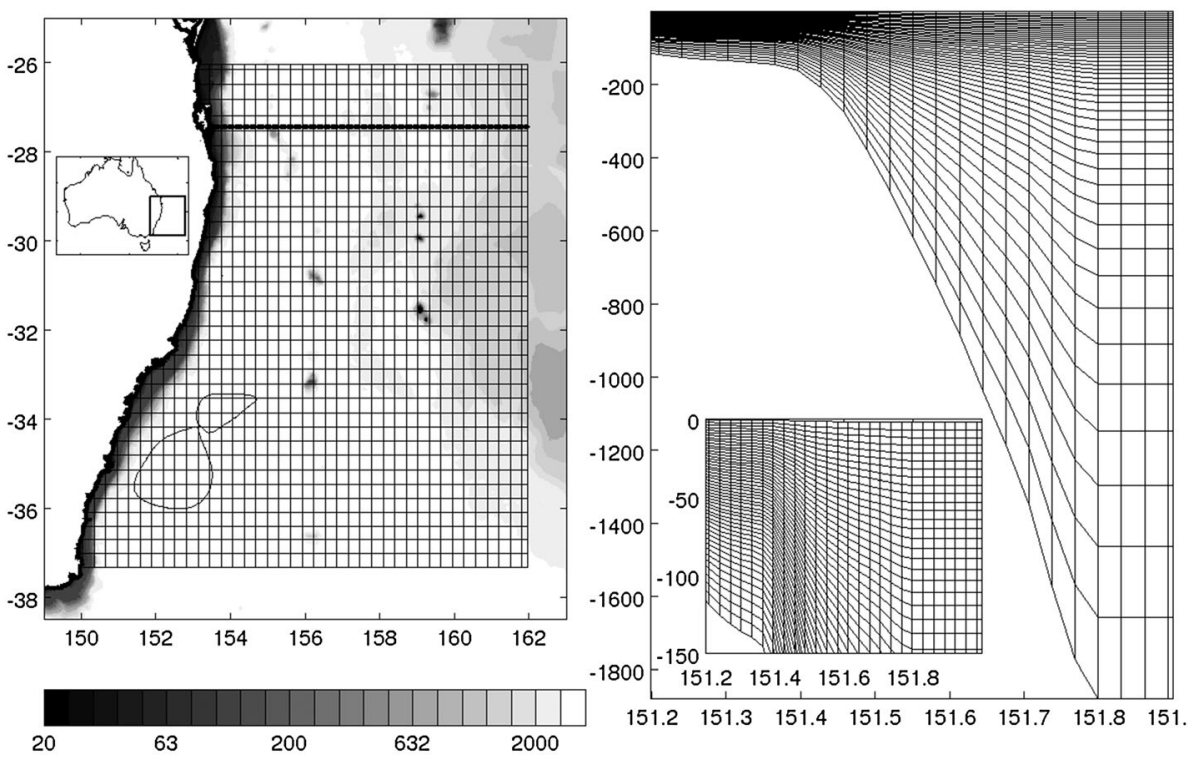

Figure 1. The model grid: (left) Horizontal resolution. Every 10th grid line is shown and the shading show bathymetry on a log scale. The thick black line in the northern section of the grid indicates the extent of the boundary nudging and the thin curves indicate the boundary of the eddy at the start and the end of the simulation. The location of the model grid is indicated by the rectangle in the insert of Australia. (right) Vertical resolution for different model depths. The insert shows the vertical resolution for the top $150 \mathrm{~m}$.

The model was initialized on 3 October 2008 (using SynTS products from 3 October) and, because it is already in geostrophic balance, has a short spinup period of 5 days. Model day 1 is 8 October.

\subsubsection{Boundary Conditions}

[16] Boundary conditions are specified for the barotropic and baroclinic velocity fields, the free surface, and tracers. The Flather [1976] condition is used for the barotropic velocity components at the northern boundary. The baroclinic velocity field and the tracers on the northern boundary are nudged to external information at a time scale of 4 days. The external SynTS fields for tracers and the baroclinic velocity components are updated during the simulation to capture the evolution over time. The Chapman [1985] condition is also applied to the northern free surface boundary. At the southern, eastern, and western boundaries radiative conditions for each of the variables are applied. Coastal boundaries are specified via a land/sea mask.

[17] There is an additional boundary nudging layer in the first 40 grid squares inward from the northern boundary. The nudging time scale is 1 day on the outer grid squares, with the strength tapered linearly to zero for the inner squares. This enables the model to be free running in the middle of the domain, south of $27^{\circ} \mathrm{S}$ (far away from the main area of study, which is south of $32^{\circ} \mathrm{S}$ ).

\subsubsection{Atmospheric Forcing}

[18] The bulk flux method of Fairall et al. [1996] is used at the atmospheric boundary to specify air-sea fluxes of heat and momentum. The wind speed is obtained from the NOAA/NCDC Blended 6 hourly 0.25 degree Sea Surface Winds data set [Zhang et al., 2006]. Longwave radiation, air pressure, relative humidity, shortwave radiation, and surface air temperature are obtained from NCEP 2.5 degree 6 hourly reanalysis data sets [Kalnay et al., 1996].

\subsubsection{The Model Grid}

[19] The model grid is modified from Wilkin and Zhang [2007]. The resolution has been increased to approximately $3.5 \mathrm{~km}$ by $4.3 \mathrm{~km}$. The resultant grid has 414 grid squares in the East/West direction and 342 grid squares in the North/South direction. This grid covers an area between $26.03^{\circ} \mathrm{S}$ to $37.33^{\circ} \mathrm{S}$ and $141.1^{\circ} \mathrm{E}$ to $161.97^{\circ} \mathrm{E}$ (Figure 1). A high resolution $(2 \times 2 \mathrm{~min})$ bathymetry from the Naval Research Lab (DBDB2 V3) has been interpolated onto this new grid. The depth of the model has been limited to $2000 \mathrm{~m}$ and the bathymetry has been smoothed using a smooth positive method [Sikiric et al., 2009] with rx0max (the target $\mathrm{rx} 0$ roughness factor) equal to 0.2 to minimize the pressure gradient error associated with terrain following models [Mellor et al., 1994].

[20] The vertical resolution has been increased from Wilkin and Zhang [2007] to more accurately depict the mixed layer. This coordinate system is implemented using 50 layers with the stretching scheme configured to obtain greater resolution in the top $250 \mathrm{~m}$ (Figure 1).

\subsection{Diagnostic Tools}

[21] A range of measures of circulation are presented in this paper because they resolve different aspects of the circulation. In this section we describe the latitudinal/depth tracer that shows the origin of water within the eddy and Lagrangian particle paths, which can show where a particular body of water (i.e., EAC water) travels to. Streamlines are used to provide a snapshot of the velocity field. This shows how the velocities on a particular day affect the tracers and particle paths.

\subsubsection{Passive Tracers}

[22] Two diagnostic passive tracers are used to visualize transport. The first, a depth tracer, is initialized throughout 

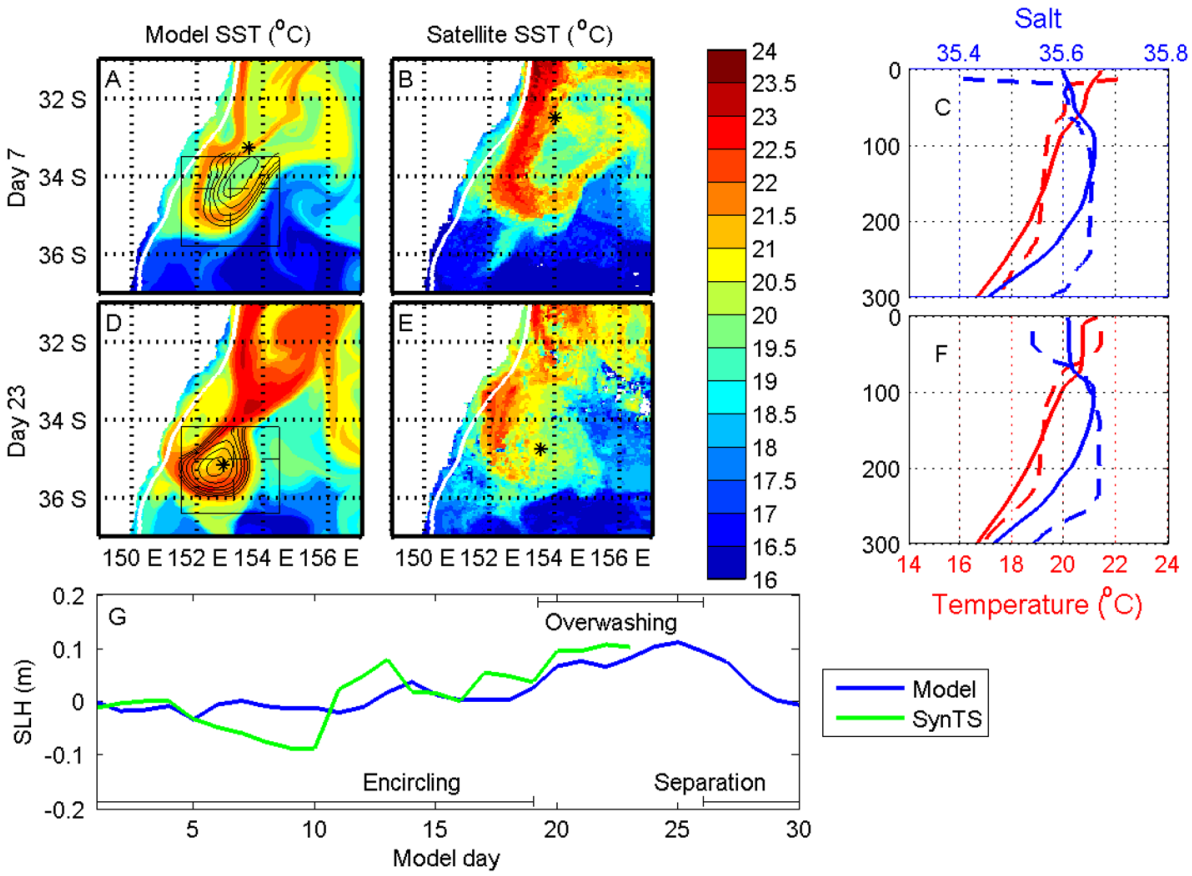

Figure 2. (a and d) Model sea surface temperature, (b and e) satellite (Advanced Very High Resolution Radiometer) SST, and (c and f) vertical profiles of temperature (red) and salinity (blue). Dashed profiles are from observational data (CTD and Argo floats) and solid profiles are from the model output. The $200 \mathrm{~m}$ isobath is indicated in white in Figures 2a, 2b, 2d, and 2e. The positions of the profiles are indicated by an asterisk for profiles from the model (Figures 2a and 2d) and for the Argo/CTD profiles (Figures $2 \mathrm{~b}$ and 2e). Each row is for a different day: (top) day 7 and (middle) day 23. The boxes indicate the positions of the 3D profiles in Figures 8, 10, and 11. (bottom) Evolution of the eddy's maximum sea-level height versus day for model (blue) and SynTS minus $0.3 \mathrm{~m}$ (green).

the domain and given the value of the depth of the grid cell in which it was initialized. It is advanced in time following the formula for advection and mixing of a conservative passive tracer having no sources or sinks. It is reset at the start of each day so that the value of the depth tracer within a particular grid cell is representative of the average initial (at the start of the day) depth of the water contained within the grid cell at that particular time. To estimate the vertical movement of the water over a day, the depth of the grid cell is subtracted from the value of the depth tracer (at the end of the day). The boundaries for the passive tracer are treated in a similar fashion to temperature and salinity with the external boundary nudging data given a value equal to the initial conditions for each day. In a similar manner, the average vertical movement of water since day 1 is calculated by only setting the tracer to its depth on day 1 of the simulation.

[23] The second passive tracer is a latitudinal tracer, which is initialized on day 1 with the value of the latitude of each water parcel on day 1 . In a similar manner to the depth tracer, the value of the latitudinal tracer at a given moment in time indicates the average initial latitude of the water contained within a grid cell.

[24] These passive tracers differ from a daily/simulation long-term average of zonal/vertical velocities because the tracers show an average while following parcels of water rather than the average of all parcels of water that pass a point. These passive tracers are a good approximation of the integration of zonal/vertical movement while following the parcels of water.

\subsubsection{Lagrangian Paths}

[25] Lagrangian particle trajectories are a useful tool for investigating transport pathways [Roughan et al., 2003, 2011]. Particles are released into the EAC on day 5 (13 October) along a transect at $31.2^{\circ} \mathrm{S}$ at approximately $1 \mathrm{~km}$ intervals between $153.2^{\circ} \mathrm{E}$ and $153.5^{\circ} \mathrm{E}$ at depths of 1,50 , and $100 \mathrm{~m}$. These particles are advected inside the model at each time step using the modeled velocities. The particles are released upstream of the eddy to show where the EAC waters enter and circulate in the eddy.

\section{Results}

\subsection{Comparison of Model and Observations of the Eddy}

[26] Model output is compared to various observations of the ocean state to assess the ability of the model to capture a WCE that formed during October 2008 (Figure 2), hereafter referred to as "the eddy". On model day 7 (14 October) the model's SST shows a WCE in a similar position and orientation to the eddy depicted in the Advanced Very High Resolution Radiometer satellite estimates of SST (Figures $2 \mathrm{a}$ and $2 \mathrm{~b}$ ).

[27] Following Chapman and Nof [1988], we will use the term "overwashing" to describe the process whereby a surface layer of fresher and/or warmer water moves onto the eddy surface. By model day 23 (30 October), the overwashing in the model (the tongue of warmer surface water) has reached the eddy center. 


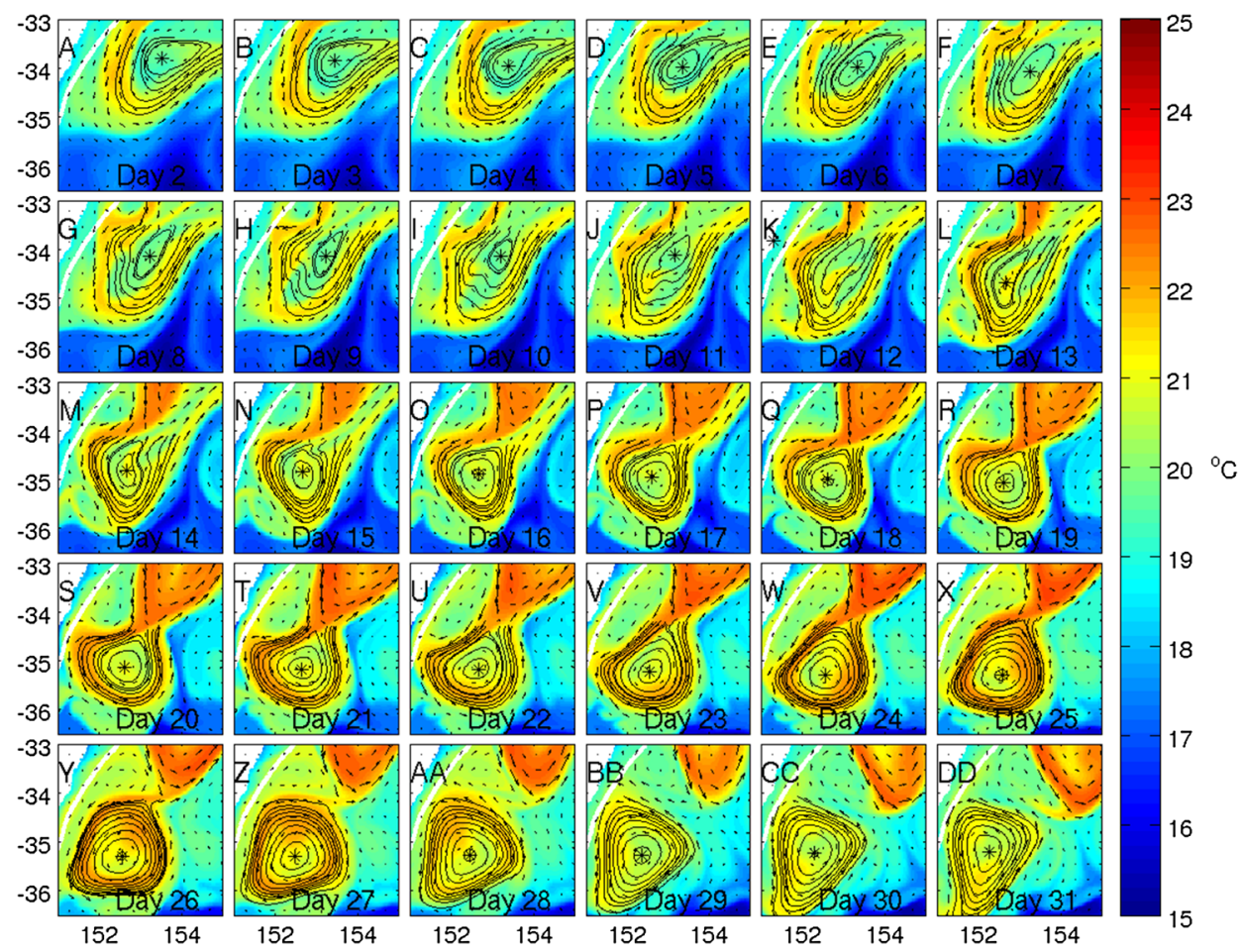

Figure 3. Model sea surface temperature $\left({ }^{\circ} \mathrm{C}\right)$ for model days 2 to 31 . The center is marked with an asterisk and sea-level contours around the eddy are shown in black. The $200 \mathrm{~m}$ isobath is shown in white.

[28] Vertical profiles of $\mathrm{T}$ and $\mathrm{S}$ in the model are compared with observations obtained from a CTD cast and an Argo float at various stages of the evolution of the eddy. The CTD cast was taken during an R/V Southern Surveyor Cruise (SS200810, CTD12) on the 14 October (model day 7). The Argo profile was taken by the Argo float 5900562, profile 147 on the 30 October (model day 23). The vertical $\mathrm{T} / \mathrm{S}$ profile on model day 7 was taken on the boundary of the EAC and the eddy at the beginning of the overwashing process. The Argo profile on day 23 was in the middle of this overwashing, located near the center of the eddy. The horizontal position of the vertical profiles in the model have been positioned to align with the same features in the observations as seen in the SST.

[29] To assess the overwashing process in subsurface layers, vertical profiles from the model are compared to observations (Figure 2, right). The impact of overwashing is evident as a subsurface homogeneous (original eddy) mixed-layer of salinity 35.65 and temperature $19.2^{\circ} \mathrm{C}$, which is capped on the surface by a warmer/less saline (EAC) layer. On model day 7 (14 October) the model has a subsurface isothermal layer ( $80 \mathrm{~m}$ to $180 \mathrm{~m}$; Figure $2 \mathrm{c}$ ), whose upper limit is in a similar position in the water column, but due to a shallower mixed layer depth in the initial conditions (SynTS) within the WCE, does not extend as deep as that of the observations $(80 \mathrm{~m}$ to $220 \mathrm{~m})$. By model day 23 (30 October; Figure 2i), the subsurface homogeneous $\mathrm{T}$ and $\mathrm{S}$ mixed-layer is at a depth of $100 \mathrm{~m}$, which is similar to the observed submerged homogeneous layer.

[30] On day 7, the EAC entering the eddy is approximately $1{ }^{\circ} \mathrm{C}$ cooler in the model than satellite (Figures $2 \mathrm{a}$ and $2 \mathrm{~b}$ ) so the resultant overwashing signature (the surface homogeneous layer in Figures $2 \mathrm{c}$ and $2 \mathrm{f}$ ) has a different temperature and salinity in the model as compared to the observations. As discussed later, there is also some mixing between the surface EAC and submerged eddy layer, which could compound this effect. In both the model and observations however, the result is a surface mixed layer on top of a subsurface homogeneous layer.

[31] The biggest difference in the model and observational profiles is at depth. The TS profiles on days 7 and 23 show an isothermal layer extending from 100 to $250 \mathrm{~m}$, a result of the deep convective mixing over winter. The model is initialized on 3 October using SynTS, which smoothes the bottom of the isothermal layer with the water below. Isolated from the surface and with low vertical mixing, this deep water maintains its TS signature over the 30 day simulation. The model mismatch at the base of the eddy is an initialization problem; however, this mismatch is not critical to the results because we concentrate on areas of the eddy above the bottom of the original eddy's mixed layer.

[32] Model sea-surface height is compared to contours of tidal-residual, isostatically-adjusted sea-level [Deng et al., 2011]. Changes in maximum sea-level height is in fairly good agreement between the model and observations (Figure 2g). Both capture the increase in sea-level height between days 10 and 23 .

\subsection{Analysis of the Model Eddy}

[33] In the model the EAC encircled the original WCE from the beginning of the simulation until overwashing began on day 19. During this encircling stage the EAC 

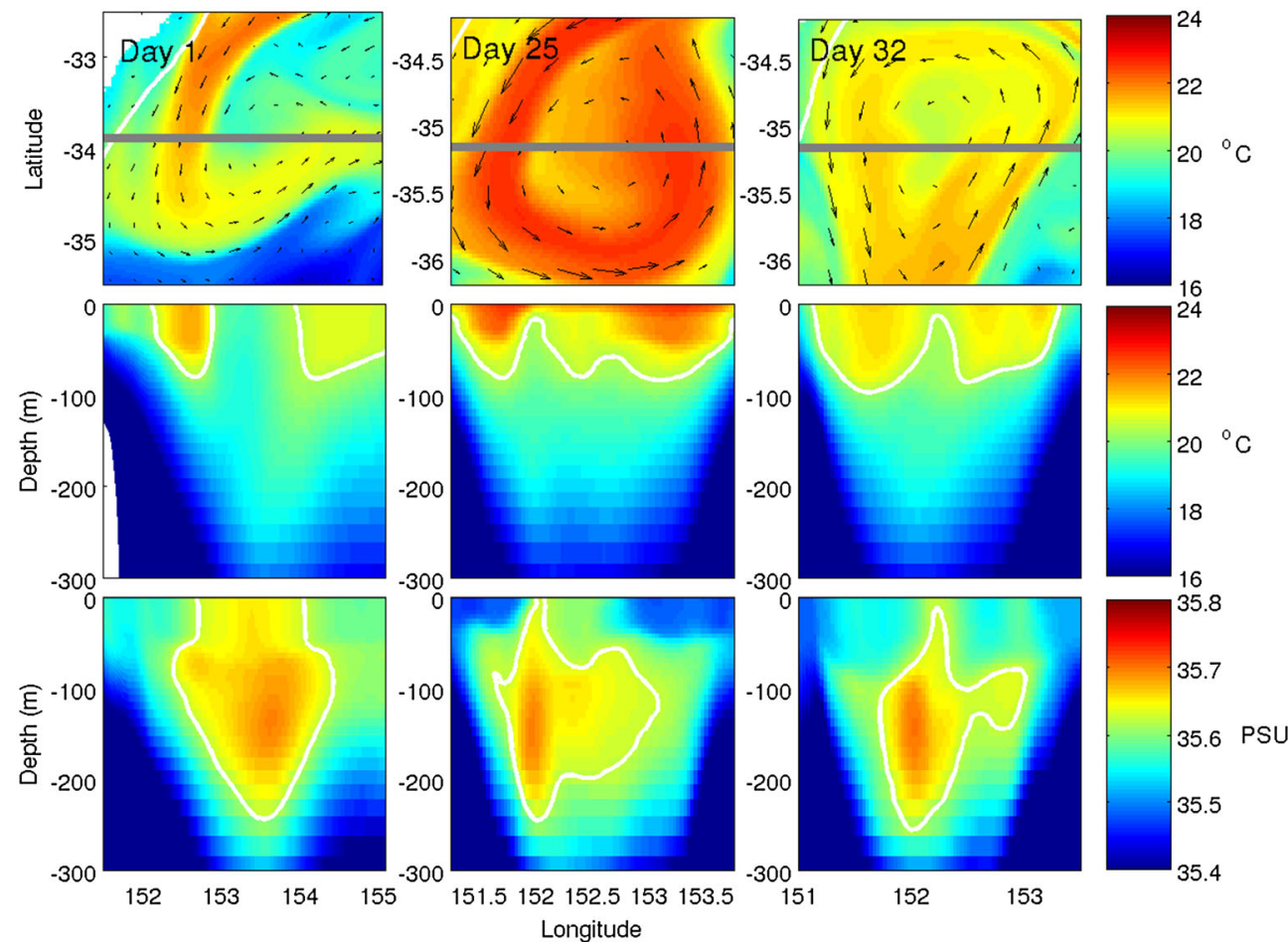

Figure 4. SST (top row) and vertical profiles of temperature (middle row) and salinity (bottom row) for days 1 (left column), 25 (middle column), and 32 (right column). The grey lines on the panels in the top row indicate the position of the vertical profiles in the bottom two rows and the white lines indicate the $200 \mathrm{~m}$ isobath. The $20.5^{\circ} \mathrm{C}$ isotherm is indicated in white on the panels in the middle row and the 35.61 isohaline is indicated on the panels in the bottom row.

extends southward around the eddy then retroflects northward, forming an anticlockwise $\mathrm{u}$-shape around the eddy (Figures $3 a-3 p)$. The eddy becomes more elliptical as it is squeezed by the retroflection (Figures $3 a-3 p$ ). Water is pushed out of the eddy to the north (Figures $3 \mathrm{~g}-3 \mathrm{n}$ ).

[34] The WCE has a temperature of $20^{\circ} \mathrm{C}$ and a salinity of 35.65-35.7 (Figure 4, left column). The overwashing occurs between days 19 and 27 when the EAC (characterized by a temperature of $21-24^{\circ} \mathrm{C}$ and a salinity of 35.5-35.6) encloses around the eddy, adding a ring of EAC waters to the eddy. Throughout the overwashing stage a thin layer of warm water from the EAC overwashes across the top of the eddy (Figure 4, middle column) as it rotates with the eddy. The EAC layer is identified as a warming of about $3^{\circ} \mathrm{C}$ along the edges of the eddy, which moves radially-inward as it moves around the eddy. The EAC which encircled the eddy (on the outer perimeter) is evident down to a depth of $50 \mathrm{~m}$ and the overwashed EAC (over the center of the eddy) has a signature down to a depth of 10-30 $\mathrm{m}$ (Figure 4). On day 27 , approximately one rotation period after overwashing began, the eddy separates from the EAC completely and evolves separately from the EAC as an overwashed WCE (Figure 3z).

[35] The overwashed EAC waters then actively mix down with the rest of the eddy (Figure 4, right column). This is evident in the deepening of the surface mixed layer depth (Figure 4, right column) combined with a cooling of the eddy surface between model days 27 to 31 (Figures $3 \mathrm{z}-3 \mathrm{dd}$ ). Thus, the surface layer becomes a mixture of eddy and EAC waters with an intact submerged layer below $100 \mathrm{~m}$.

\subsection{Vorticity}

[36] A typical eddy has a vorticity maximum at the center with the vorticity decreasing radially outward. In this simulation this holds true for the eddy at depths below the eddy/ EAC interaction (Figure 5) but not at the surface (Figure 6). In a similar manner to temperature, the EAC which encircles the eddy initially (Day 7-19) has a greater vorticity than the eddy. This leads to a reversed vorticity gradient with the vorticity increasing radially outward at the surface.

[37] In addition to this reversed vorticity gradient, the eddy forms with cyclonic vorticity at the interface of the eddy and the EAC (thin blue filament in Figure 6). This cyclonic vorticity moves into the center of the eddy between days 2 and 9 and is then expelled from the eddy between days 13 and 18 .

[38] The expulsion of cyclonic waters allows the overwashing of a filament of high vorticity waters leading to an increase of vorticity at the center of the eddy. At the start of the simulation, the center of the eddy had a vorticity ranging from $-2 \times 10^{-5}$ to $1.5 \times 10^{-5} \mathrm{~s}^{-1}$, which increased to around $2.5 \times 10^{-5} \mathrm{~s}^{-1}$ by the end of the simulation. The vorticity of the outside ring of the eddy decreases during this vorticity transfer from a range of $3.4 \times 10^{-5}$ to $4 \times$ $10^{-5} \mathrm{~s}^{-1}$ at the start of the simulation to a range of $1.5 \times 10^{-5}$ to $2.5 \times 10^{-5} \mathrm{~s}^{-1}$ at the end of the simulation.

\subsection{Water Movement Within the Eddy}

[39] Streamlines can define the subsurface boundary of an eddy while giving a snapshot of the velocity field at a particular time. In particular, they show regions of upwelling and 


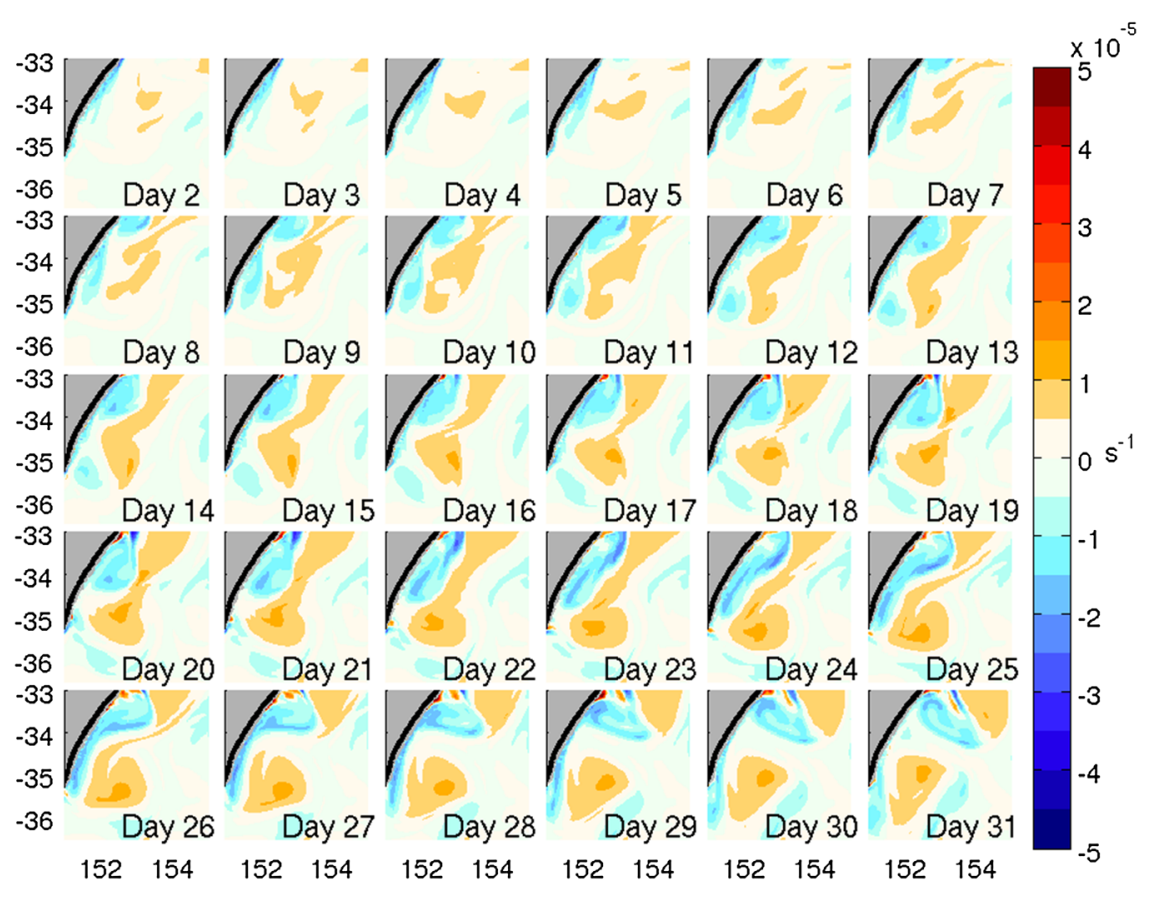

Figure 5. Vorticity $\left(\mathrm{s}^{-\mathbf{1}}\right)$ at $500 \mathrm{~m}$ depth for model days 2 to 31 . Negative (blue) indicates cyclonic vorticity and positive (red) indicates anticyclonic vorticity. The $200 \mathrm{~m}$ isobath is indicated in black.

downwelling. The passive tracers and the Lagrangian paths of the next section show the movement of water parcels. Streamlines differ from this as they capture the structure of the current field of the eddy at a given time. Because it can take up to 8 days to complete a rotation around the eddy, the streamlines may have changed during that time, so it should be noted that these are not an indication of the path that a particular particle within the eddy will take.

[40] Streamlines are calculated from the daily averaged 3D velocity field with an initial position located through an east/ west transect from the outside to the center of the eddy (by $0.05^{\circ}$ intervals from $152.6^{\circ} \mathrm{E}$ to $153.1^{\circ} \mathrm{E}$ at $34^{\circ} \mathrm{S}$,

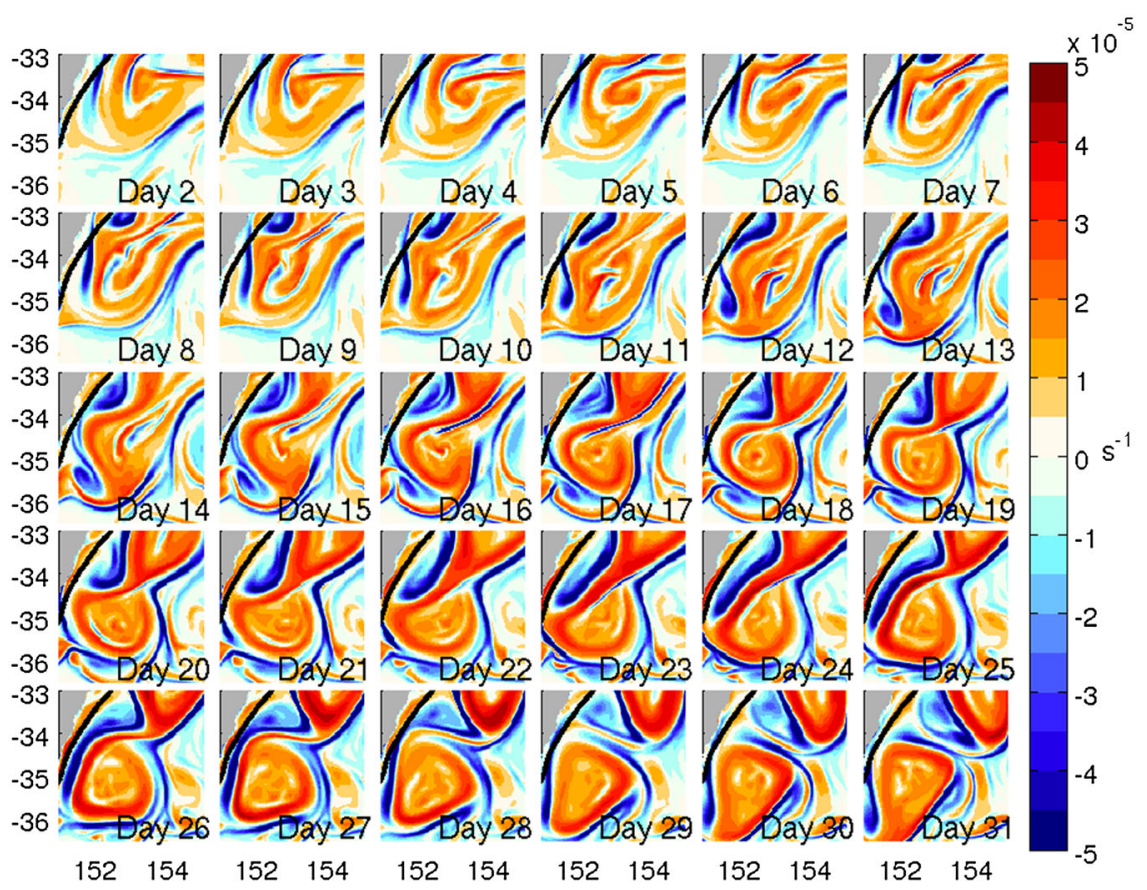

Figure 6. Surface vorticity $\left(\mathrm{s}^{-\mathbf{1}}\right)$ for model days 2 to 31 . Negative (blue) indicates cyclonic vorticity and positive (red) indicates anticyclonic vorticity. The $200 \mathrm{~m}$ isobath is indicated in black. 

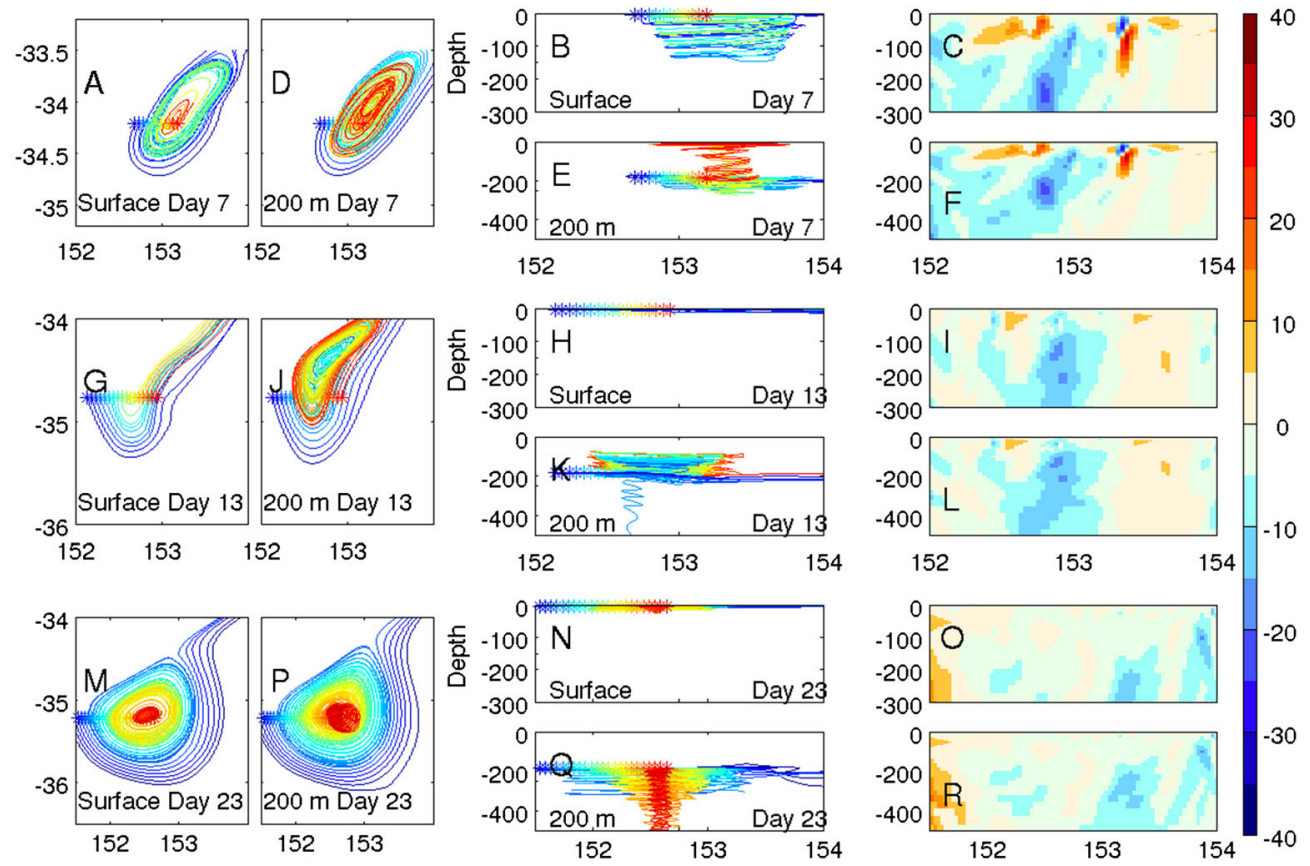

Figure 7. Streamlines calculated with 10,000 steps of $1 / 10$ of cell (of size $0.1^{\circ} \times 0.1^{\circ} \times 10 \mathrm{~m}$ ) and vertical velocities within the eddy. A view of the streamlines is shown on top (left) and one side (middle). Streamlines from two different depths are shown (surface and $200 \mathrm{~m}$ ). Colors show radial distance at the beginning of the streamline. This is on model day 7 (Figures 7a, 7b, 7d, and 7e), model day 13 (Figures $7 \mathrm{~g}$, $7 \mathrm{~h}, 7 \mathrm{j}$, and $7 \mathrm{k}$ ) and model day 23 (Figures $7 \mathrm{~m}, 7 \mathrm{n}, 7 \mathrm{p}$, and 7q). (right) Vertical transect of the vertical components of velocity $\left(\mathrm{m} \mathrm{d}^{-\mathbf{1}}\right.$ ) through the eddy on model days 7,13 , and 23 (corresponding to the streamlines on the left). A red velocity is an upward velocity and a blue velocity is a downward velocity. The velocity fields used in this figure are daily averages. Note an asterisk indicates the starting points. Day 7 (Figures 7a-7f), Day 13 (Figures 7g-71), and Day 23 (Figures 7m-7r).

$152.1^{\circ} \mathrm{E}$ to $153^{\circ} \mathrm{E}$ at $34.6^{\circ} \mathrm{S}$ and $151.5^{\circ} \mathrm{E}$ to $154.9^{\circ} \mathrm{E}$ at $35.4^{\circ} \mathrm{S}$ on model days 7,13 , and 23 , respectively). This is conducted with streamlines originating at $1 \mathrm{~m}$ and repeated at $200 \mathrm{~m}$ depth giving a $3 \mathrm{D}$ picture of the flow within the eddy.

[41] On model day 7 (14 October; Figures 7a-7f) the streamlines indicate that there is a large eddy that extends vertically through the water column as evidenced by the closed streamlines at 0 and $200 \mathrm{~m}$ (Figures 7a and 7d). There is a flow of EAC water encircling the eddy that exits in a northeast direction. Most of the streamlines at both depths are spiraling down (Figures $7 \mathrm{~b}$ and $7 \mathrm{e}$; indicating downward spiral of water in this section of the eddy). The exception to this is a small area in the center at $200 \mathrm{~m}$ depth where the streamlines spiral up to the surface due to a small but intense upwelling (shown by red lines; Figure 7e).

[42] On model day 13 (20 October; Figures 7g-71) the surface streamlines are not closed (Figure $7 \mathrm{~g}$ ). This means that they leave the eddy rather than completing a $360^{\circ}$ rotation around the eddy. This is due to flow into and out of the eddy, essentially flushing out most of the surface waters of the eddy. At $200 \mathrm{~m}$ depth the streamlines are closed, indicating that the flushing only occurs in the surface and that an eddy still exists underneath (Figure $7 \mathrm{j}$ ). There is a small amount of downwelling in the center of the eddy but an upward spiral of water on the edge of the eddy (Figure 7k). This shows a tendency for the water to downwell at the center but upwell near the edges (opposite to day 7).
[43] By model day 23 (30 October; Figures 7m-7r), during the overwashing, the surface streamlines have closed again (Figure $7 \mathrm{~m}$ ). This leaves a large eddy enclosed by the streamlines. In the middle of the eddy the water is trapped at the surface, with no downward spiral. At depth there is downwelling so that the lateral transport into the eddy from the surface overwashing current is balanced by the downward movement of water (Figure 7q; note that the maximum horizontal convergence is subsurface so that the surface streamlines do not downwell).

\subsubsection{The Subsurface Temperature of the Eddy}

[44] The 3D structure of the eddy's temperature is visualized by removing the southwest quadrant to show vertical sections along $35^{\circ} \mathrm{S}$ and $153^{\circ} \mathrm{E}$. The EAC can be seen by the warmer water around the edge of the eddy (Figure $8 b$ ). Ten days later (model day 23; 30 October) the EAC has overwashed the eddy and has formed a layer (20-90 m thick) of $24^{\circ} \mathrm{C}$ water on top of the eddy.

\subsection{Movement of Water}

[45] During the simulation EAC waters enter and exit the eddy at the northern end. On day 24 in the surface, the net flow for areas above $285 \mathrm{~m}$ through a transect north of the eddy is $5 \mathrm{~Sv}$ into the eddy (not shown). This extra water entering the eddy will either result in water leaving the eddy, the eddy growing, or the surface waters sinking. On day 24, 1.2 Sv of the incoming water is balanced by sinking water. 


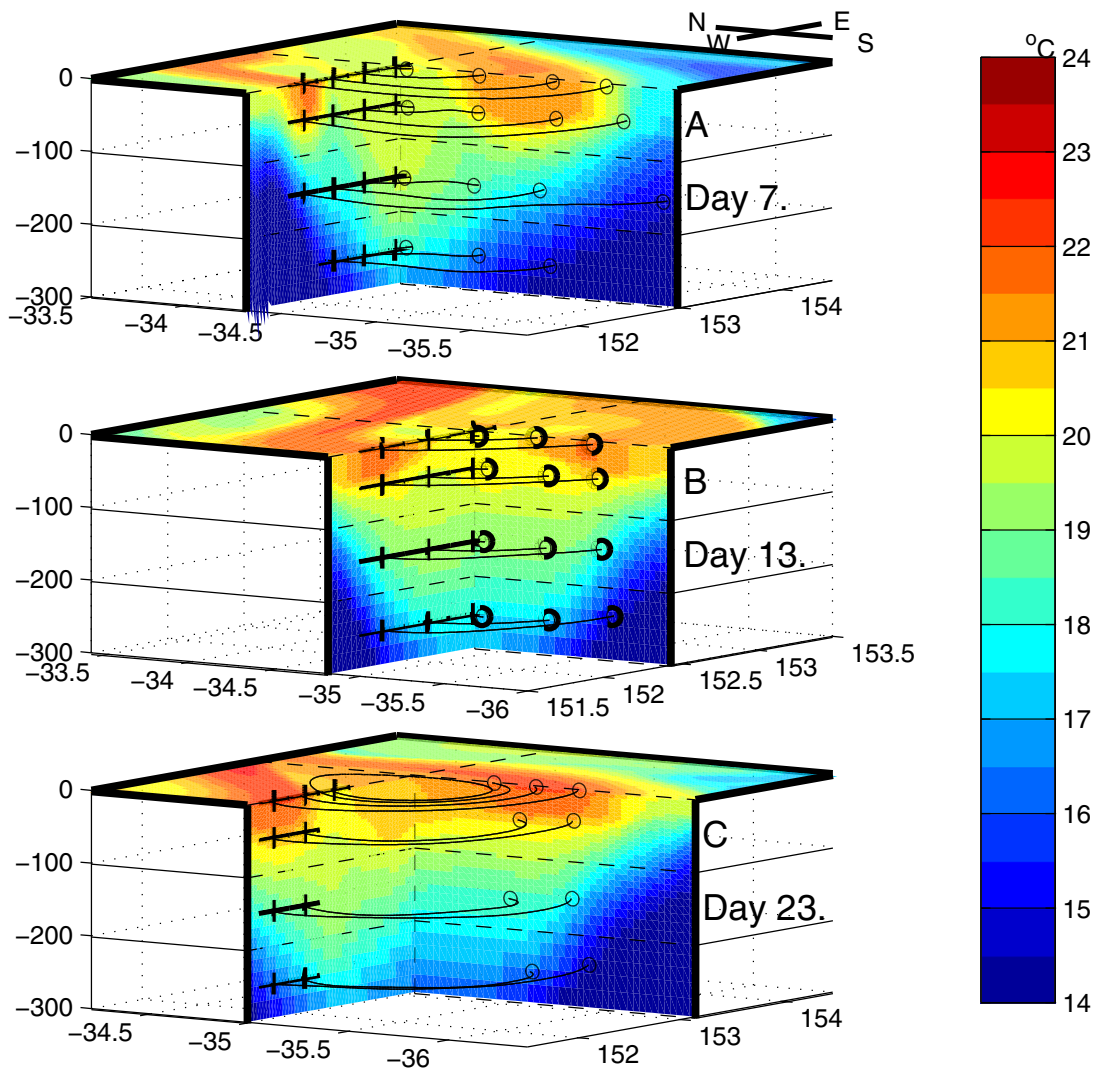

Figure 8. 3D profiles of temperature $\left({ }^{\circ} \mathrm{C}\right.$ ) from (top) model day 7, (middle) day 13 , and (bottom) day 23. Streamlines within the eddy are shown as an indication of the eddy boundary. These streamlines are initialized along the west/east line $\left(34.3^{\circ} \mathrm{S}\right.$ in Figures $8 \mathrm{a}$ and $8 \mathrm{~b}$ and $35^{\circ} \mathrm{S}$ in Figure $\left.8 \mathrm{c}\right)$ at surface, 100 and $200 \mathrm{~m}$ depth at $0.3^{\circ}$ longitude intervals. Only those streamlines that stay within the eddy are shown.
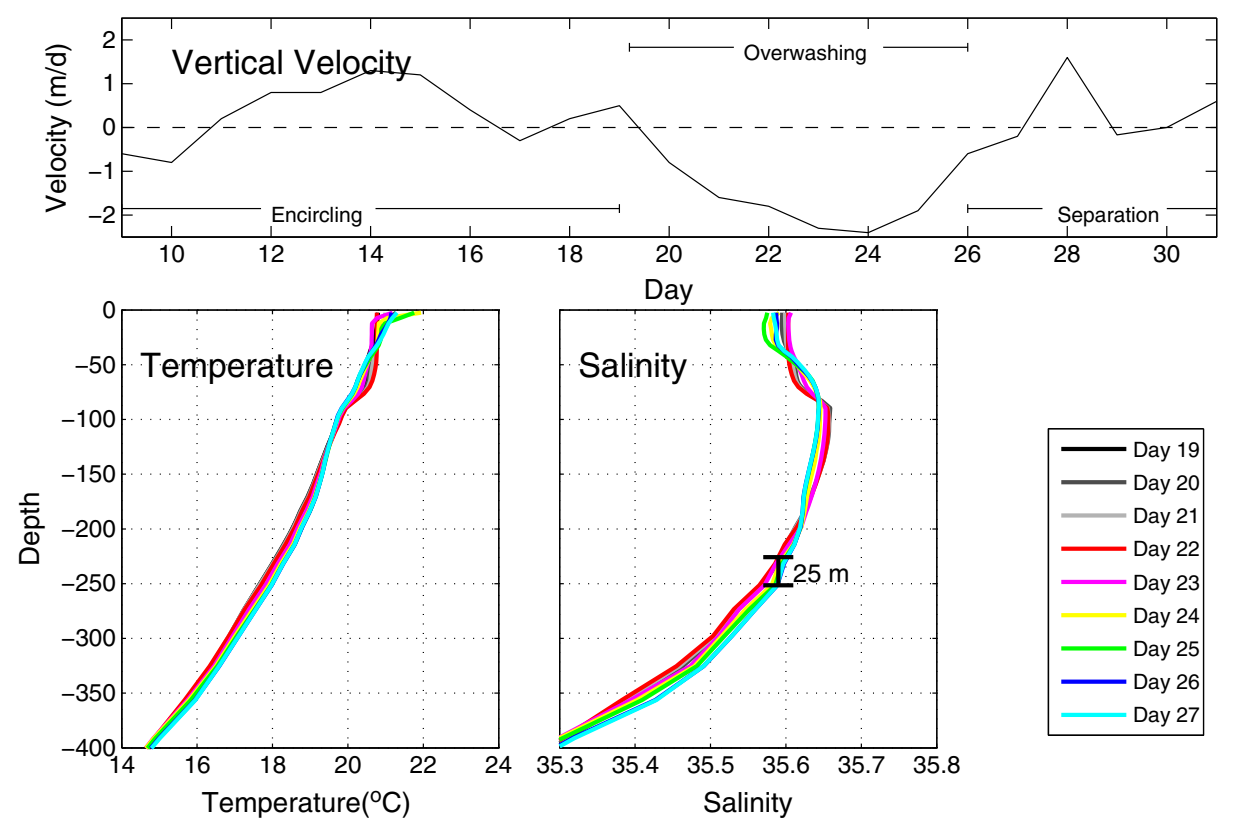

Figure 9. (top) Average vertical velocity at $285 \mathrm{~m}$ in the eddy. Negative indicates downward movement and positive indicates upward movement. Profiles of temperature (bottom left) and salinity (bottom right) through the center point (as defined by the highest sea-level elevation) of the eddy. These profiles are for days 19 to 27 , colored as indicated by the legend. The vertical movement of the isohalines is indicated on the right. 

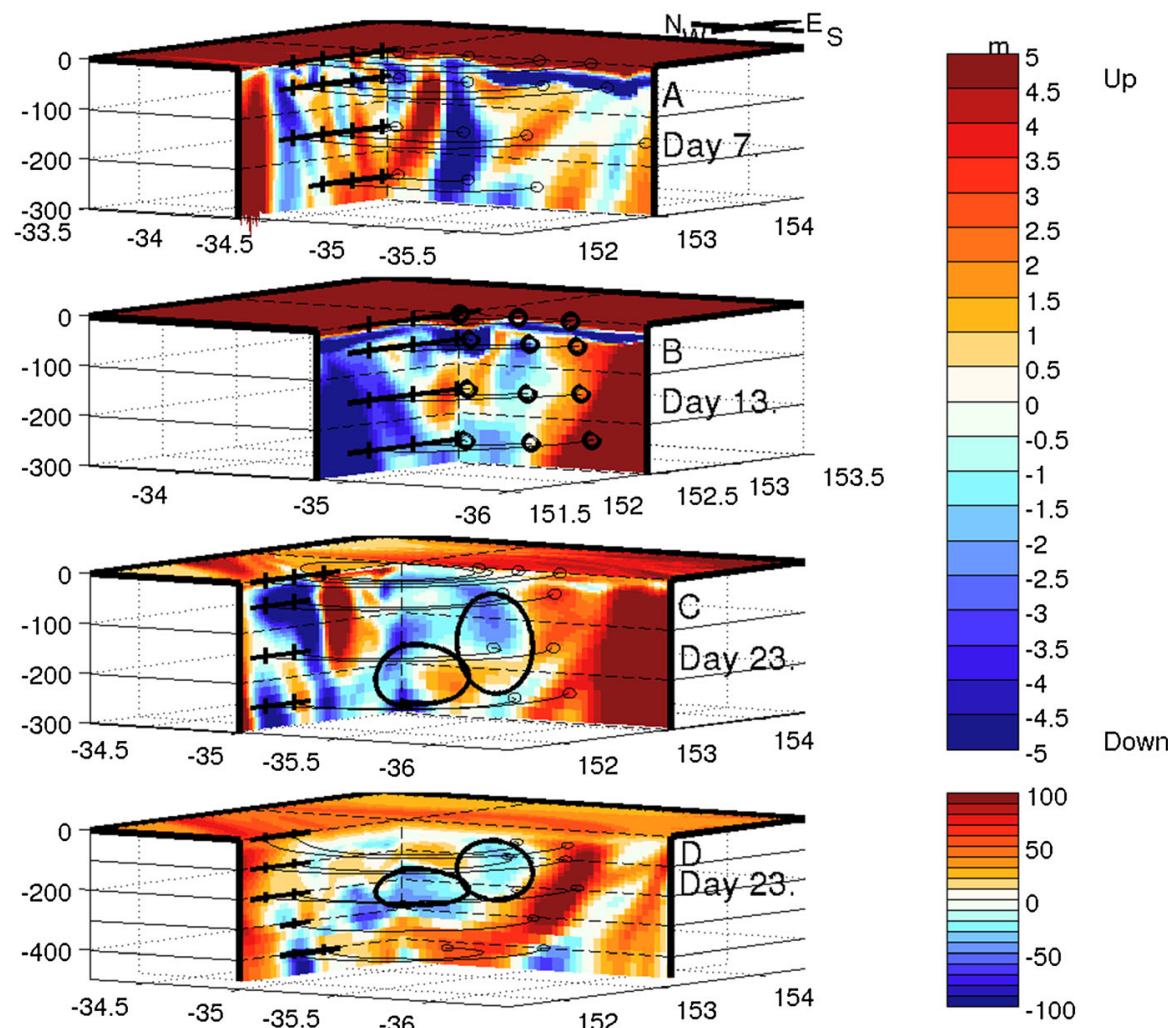

Figure 10. 3D profiles of depth tracer. This is the change in tracer concentration over the period of a day for (a) model day 7, (b) model day 13, and (c) model day 23. Red indicates that the water has been uplifted and blue indicates that it has been downwelled over the period of a day. (d) Vertical movement of water between the beginning of the simulation and day 23. Note the depth limits in Figure 10d go down to $500 \mathrm{~m}$. Streamlines within the eddy are shown as an indication of the eddy boundary. These streamlines are initialized along the west/east line $\left(34.3^{\circ} \mathrm{S}\right.$ in Figures $10 \mathrm{a}$ and $10 \mathrm{~b}$ and $35^{\circ} \mathrm{S}$ in Figures $10 \mathrm{c}$ and $\left.10 \mathrm{~d}\right)$ at surface, 100 and $200 \mathrm{~m}$ depth at $0.3^{\circ}$ longitude intervals. Only those streamlines that stay within the eddy are shown. The black ovals indicate the areas referenced in section 3.5, which are submerged original eddy waters.

The remainder is ejected from the eddy or contributes to the growth of the eddy. This section looks at the sinking waters.

[46] Between days 19 to 27 the vertical velocity in the eddy becomes a strong, downward flow, averaging $1.4 \mathrm{~m} \mathrm{~d}^{-1}$ (Figure 9, top). Over this period, the average sinking in the eddy is $11.4 \mathrm{~m}$. After day 27 the eddy separates from the EAC, eliminating the source of EAC waters to the eddy and sinking stops.

[47] This sinking is also evident in profiles of temperature and salinity (Figure 9, bottom right and left). Temperature and salinity profiles through the center of the eddy show that, at depths below $100 \mathrm{~m}, \mathrm{~T}$ and $\mathrm{S}$ properties sink by $10-25 \mathrm{~m}$ over days $19-27$. The spatial extent of this downward vertical movement is also evident in the depth tracer.

[48] The depth tracer quantifies the vertical movement of water over the course of a day (Figures 10a-10c) or from the time since model day 1 (Figure 10d). The 3D structure of the tracer properties within the eddy are visualized by removing the southwest quadrant to show vertical sections along $35^{\circ} \mathrm{S}$ and $153^{\circ} \mathrm{E}$ (in a similar manner to Figure 8). A layer of water that has risen, sitting above a layer of water that has sunk (i.e., red on blue), can be a result of vertical mixing. This is evident in the surface layer of the eddy from model day 7 (14 October; Figure 10a).
[49] During the overwashing (day 23; 30 October; Figure 10c), the submergence is occurring in the eddy center and water from the edge of the eddy is being uplifted.

[50] Over the course of the simulation, up to model day 23 (30 October; Figure 10d), there is a subducted area in the south of the eddy $\left(35^{\circ} \mathrm{S}-35.7^{\circ} \mathrm{S}\right.$, along the $153^{\circ} \mathrm{E}$ line). This core of the eddy (originally sitting at $0-200 \mathrm{~m}$ depth) has sunk $20-90 \mathrm{~m}$ since the beginning of the simulation.

[51] To be confident that the depth tracer is indicative of vertical advection and not unduly affected by vertical mixing, we estimated the vertical profile of vertical Peclet number $P e=w L / A_{\mathrm{v}}$, where $w$ is the vertical velocity, $L$ is a length scale and $A_{\mathrm{v}}$ is the vertical diffusivity. Where this ratio is large the role of turbulent mixing is small compared to advection and the tracer results are a reliable marker of vertical water movement.

[52] The model calculates $A_{\mathrm{v}}$ using the turbulent closure scheme of Mellor and Yamada [1982] based on instantaneous velocity shear and stability of the flow. In the MellorYamada closure, static instability elevates $A_{\mathrm{v}}$ during convective events, so in order to estimate the diffusivity that occurs most often, we took the median value within the eddy and over an ensemble of model snapshots. This was noted at $50 \mathrm{~m}$ vertical intervals from the surface to $300 \mathrm{~m}$ depth. The 


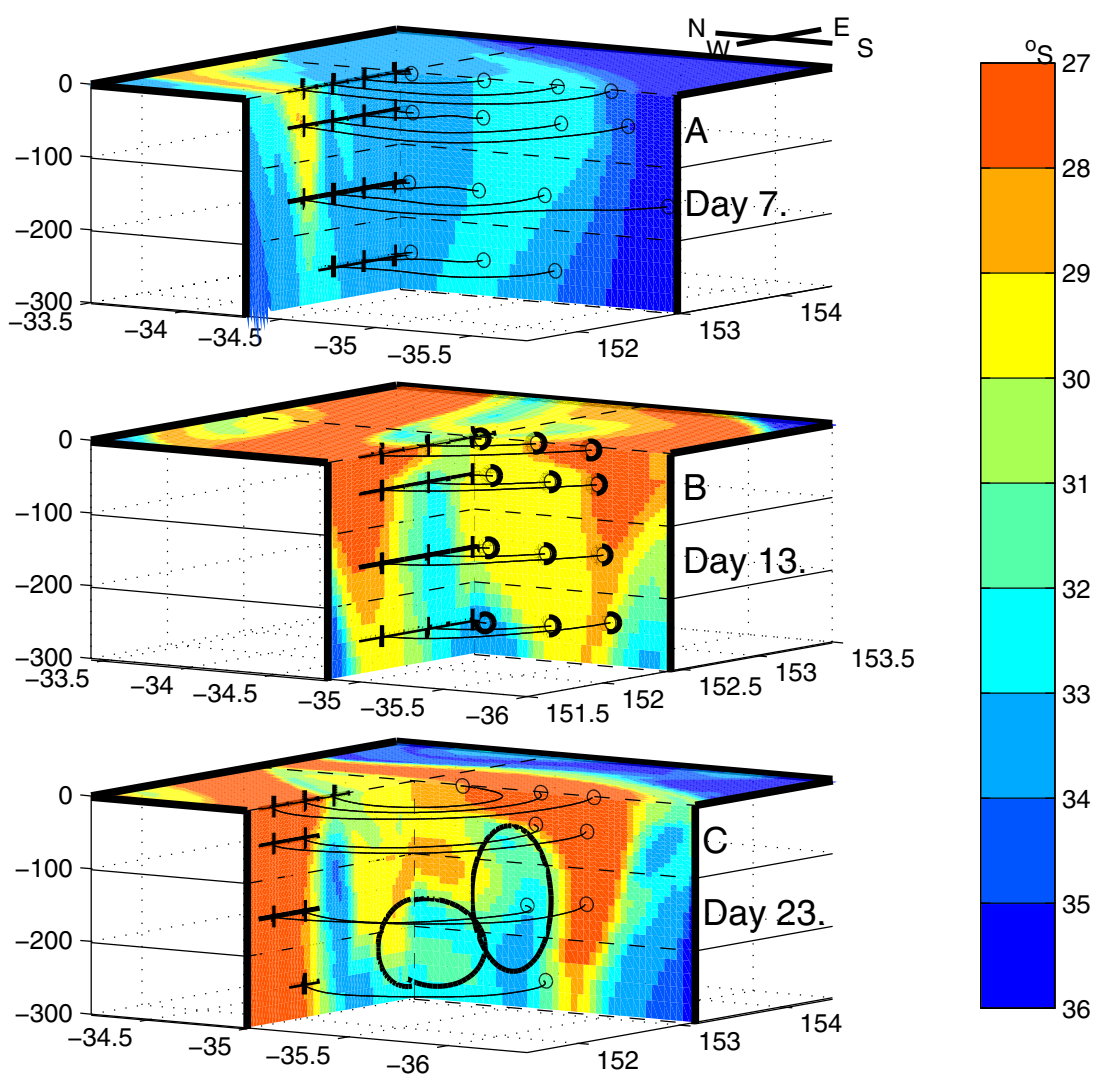

Figure 11. 3D profiles of latitude tracer from model day 7 (top), 13 (middle) and 23 (bottom). Red indicates water that has originated from the north and blue indicates water that has originated from the south. Streamlines within the eddy are shown as an indication of the eddy boundary. These streamlines are initialized along the west/east line $\left(34.3^{\circ} \mathrm{S}\right.$ in Figures $11 \mathrm{a}$ and $11 \mathrm{~b}$ and $35^{\circ} \mathrm{S}$ in Figure $\left.11 \mathrm{c}\right)$ at surface, 100 and $200 \mathrm{~m}$ depth at $0.3^{\circ}$ longitude intervals. Only those streamlines that stay within the eddy are shown. The black ovals indicate the areas referenced in section 3.5, which are submerged original eddy waters.

length scale chosen was the depth below surface. The surface mixed layer within the eddy is 50-100 $\mathrm{m}$ deep (Figure 9), and shallower than $100 \mathrm{~m}$ we see the Peclet number falls below 1 indicating that turbulent mixing is indeed significant. However, below $100 \mathrm{~m}$ depth the Peclet number is large (greater than 10) supporting our interpretation of the depth tracer as being dominated by vertical advection

[53] The latitudinal tracer (Figure 11) indicates the latitude at which a parcel of water was either located on model day 1 , or entered into the model domain. The eddy's initial latitudinal range was $33-35^{\circ} \mathrm{S}$ and the EAC entering the model domain from the northern boundary is given a value of $26.03^{\circ} \mathrm{S}$. During the overwashing (model day 23 ), water from the original eddy $\left(33^{\circ} \mathrm{S}\right)$ can easily be differentiated from the EAC water that encircled the eddy (Figure 11c). On model day 7 (14 October; before the overwashing begins) the EAC can be seen encircling the eddy. By model day 13 the EAC is still rotating around the eddy and a small amount of EAC waters can be seen near the centre of the eddy.

[54] By model day 23 (30 October) the eddy has grown and the EAC has flushed the eddy. A small core of original eddy waters exist at $35-35.7^{\circ} \mathrm{S}$ along the $153^{\circ} \mathrm{E}$ line, corresponding to regions of sinking (circled in Figures $11 \mathrm{e}$ and 10d). This shows that there is a small part of the eddy that has been submerged due to the surface overwashing, leaving an EAC layer above the original eddy.

[55] The rest of the eddy has a small portion of EAC waters $\left(27^{\circ} \mathrm{S}\right)$ in the surface $50 \mathrm{~m}$, and water from $31^{\circ} \mathrm{S}$ to $28^{\circ} \mathrm{S}$ in the lower waters. This signal could be water that originated in the EAC at approximately $30^{\circ} \mathrm{S}$, or a mixture of EAC and eddy waters.

\subsection{Lagrangian Pathways Within the EAC}

[56] To investigate the Lagrangian pathways of the EAC around and over the eddy, particles are released on day 5 in the EAC upstream (north at $31.2^{\circ} \mathrm{S}$ ) of the eddy at the surface, 50 and $100 \mathrm{~m}$ depth (Figure 12). Upstream of the eddy there is little vertical movement within the EAC, so when the particles reach the eddy they are at a similar depth as their starting position (Figure 12, bottom row). Between days 13 and 25 the EAC (and Lagrangian particles) enters the eddy. How these particles enter the eddy differs for particles released at different depths.

[57] The surface release particles flow onto the top and into the middle of the eddy with the surface overwashing current. These particles then sink with the eddy. Most of the particles released at 50 and $100 \mathrm{~m}$ depth rotate around 

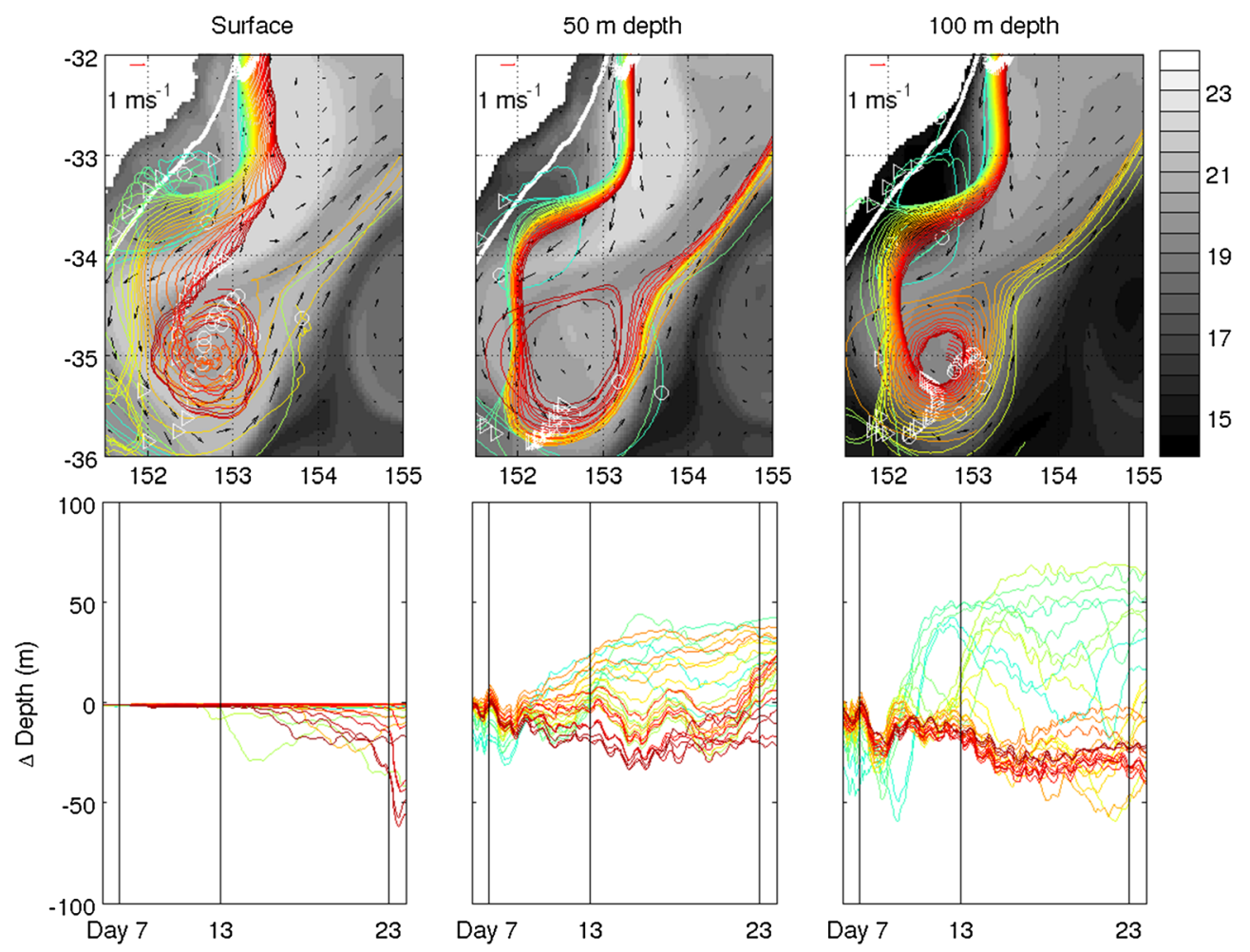

Figure 12. Lagrangian paths of particles released on day 5 within the EAC: (left) at the surface, (middle) 50-60 m, and (right) $100-120 \mathrm{~m}$. The top row shows the horizontal view of the particle tracks and the bottom shows the vertical displacement of the particles versus time. The colors of each particle in the top row correspond to the colors of the particles in the bottom row. A white asterisk in the top row indicates the particle position on day 7 , a triangle indicates the particle position on day 13, and a circle indicates the particle position on day 23 . The shading indicates temperature and the arrows indicate velocity (direction and relative speed) on model day 5 for each of the three depths (surface, $50 \mathrm{~m}$, and $100 \mathrm{~m}$ from left to right).

the eddy and leave with the EAC through the northeast corner. Some (about a third) join the eddy as the EAC closes around, forming a complete loop. Unlike the surface release particles (which move into the centre of the eddy with the overwashing EAC), these particles stay on the periphery of the eddy.

\section{Discussion}

\subsection{Buoyancy}

[58] The eddy grows in the EAC retroflection by the transfer of vorticity and energy from the EAC into the eddy. In the case study here, overwashing provides a process for this energy transfer to occur. The density gradient between a WCE and surrounding waters is such that, typically the eddy is more buoyant than the surrounding waters, making movement over the eddy (or overwashing) impossible (without another forcing). However, in the case presented here, the surface density gradient between the WCE and the EAC is reversed to that of a typical eddy, i.e., the surrounding (EAC) waters are more buoyant than the eddy waters. As such, a process such as overwashing is expected. Despite this buoyancy difference, the overwashing did not occur from the beginning of the simulation. Why this is the case can be answered by looking at the evolution of vorticity within the eddy.

\subsection{What Causes the Overwashing?}

[59] During the simulation the eddy transforms from an unstable eddy where the vorticity gradients increase outward (i.e., the density distribution is not at its lowest state of potential energy) to a stable (typical) eddy where the vorticity gradients decrease outward. The eddy begins in a state of disequilibrium with a higher vorticity ring on the outside. Cyclonic vorticity (Figure 6; at the density front between the EAC and the eddy) acts as a barrier to prevent this high vorticity EAC water from entering the eddy. During days 7 to 18 the waters of cyclonic vorticity are expelled from the eddy and a filament of high-vorticity water is pulled from the EAC into the center of the eddy. The vorticity intensification at the eddy center results in convergence and downwelling. This in turn pulls in more high-vorticity filaments of water from the EAC ring around the edge of the eddy. This feeds the vorticity intensification and, from day 19, there is high vorticity water spiraling into the eddy center. The question remains, what caused the eddy to expel the cyclonic vorticity waters?

[60] A WCE will have surface convergence and downwelling when it is forming and, as such, the WCE should naturally pull in water from the warmer surrounding ring. The cyclonic vorticity made the eddy unstable so that it expelled water to the north. Once the cyclonic vorticity had been 

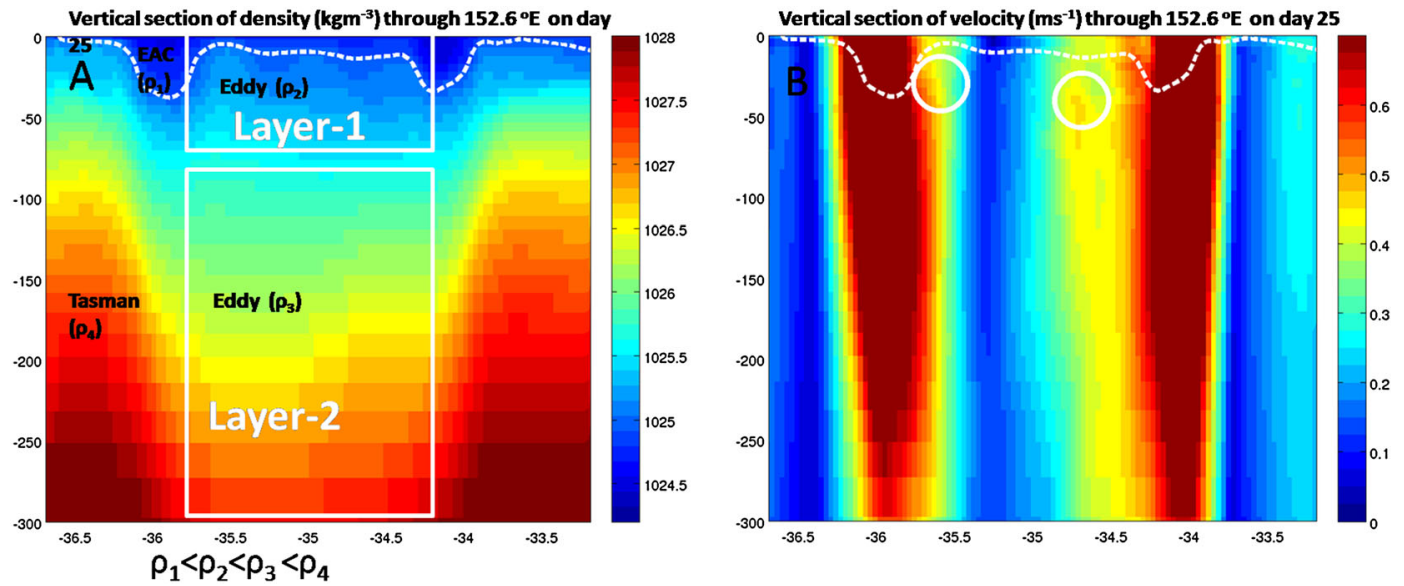

Figure 13. A density cross-section through the eddy at $152.6^{\circ} \mathrm{E}$ on day 25 (left). The layer in which the EAC is overwashing (Layer 1) and the traditional eddy layer (Layer 2) are indicated. Right: a vertical cross-section of horizontal velocity magnitude through the eddy at $152.6^{\circ} \mathrm{E}$ on day 25 . The white circles indicate positioning of subsurface velocity maximums. The dashed white density contour on both left and right $\left(1024.9 \mathrm{~kg} \mathrm{~m}^{-3}\right)$ indicates the overwashing EAC.

expelled, the areas of divergence associated with the cyclonic waters disappeared, and the eddy transformed to a more balanced state (convergent in the center, pulling in water from the warm-ring on the edge). This then drove the overwashing of water from the EAC (and even perhaps separation of the eddy).

\subsection{Conceptual Model of the Overwashing Process}

[61] The overwashing process results in a two-layered system (for this conceptual model divided at a depth of around $70 \mathrm{~m}$; Figures 13a and 13b). The bottom layer (layer 2) is a classical WCE with a warm, less dense center and density increasing radially outward. The top layer (layer 1) extends from $70 \mathrm{~m}$ to the surface and is where the EAC is interacting with the eddy. In the top layer the depth of the (encircled) EAC is deeper on the outside ring of the eddy than the depth of the (overwashed) EAC on the eddy surface. Thus, the density in the top layer decreases radially outward as the EAC (overwashing from the outer edge initially and then moving toward the centre of the eddy) is less dense than the eddy.

[62] To show the contributions of each layer to the overall velocity field, we investigate the geostrophic currents using the dynamic height anomaly in each layer. Because the dynamic height anomaly of the bottom layer will contribute to the overall geostrophic currents of the upper layer (i.e.,

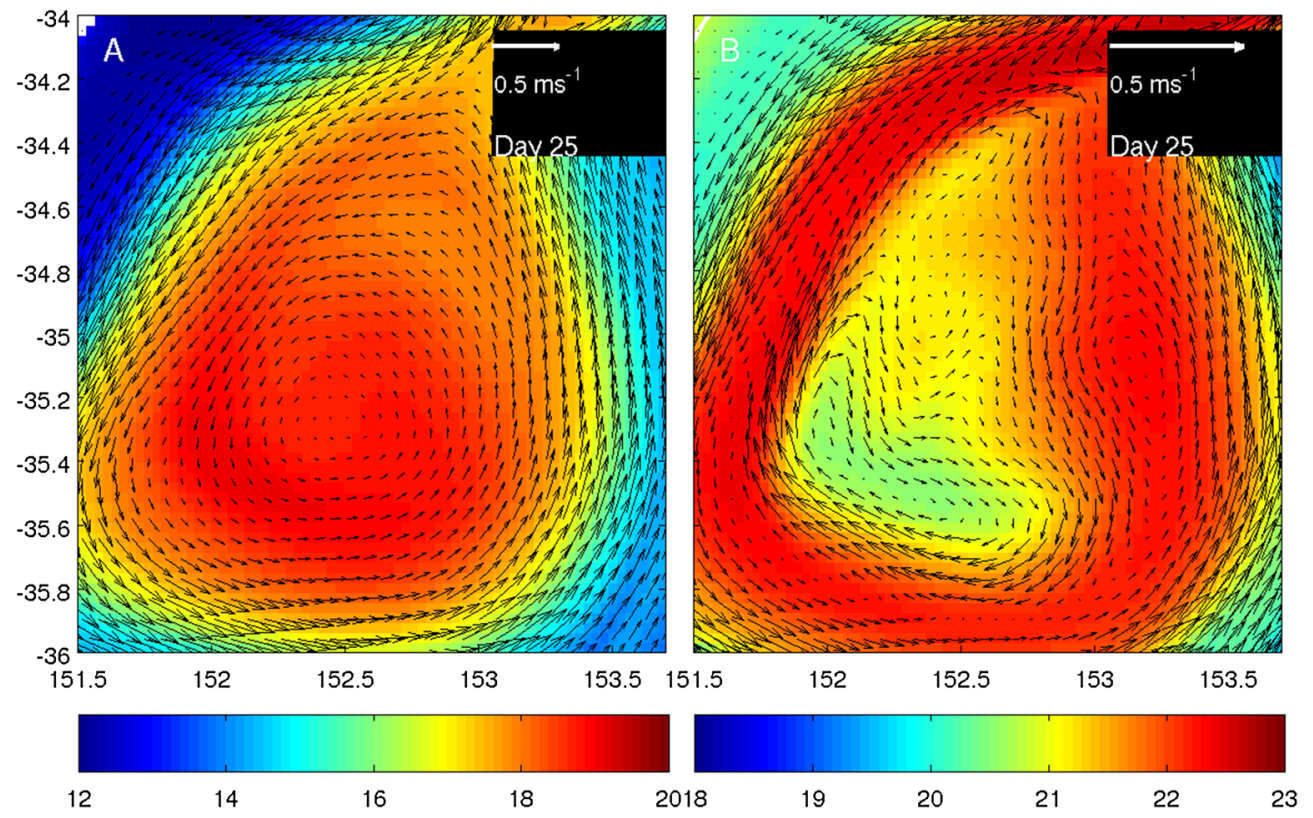

Figure 14. Temperature (a) at a depth of $100 \mathrm{~m}$ and (b) at the surface on day 25. Arrows represent the geostrophic velocity through the water column (Figure 14a) and in the top layer (Figure 14b), i.e., assuming a level of no motion at a depth of $100 \mathrm{~m}$. Note the velocity scale is different between the two panels. 
from $100 \mathrm{~m}$ to the surface), the currents in the top layer are calculated assuming no height anomaly at $100 \mathrm{~m}$ depth.

[63] Although the WCE is rotating anticyclonically, there is a cyclonic component of the velocity field along the front between the EAC and the WCE (Figures 14b and 6, Day 25). This cyclonic component of velocity, although small relative to the surface velocity, is opposite to that of the anticyclonic flow of the eddy (Figure 14). The resultant velocity is an anticyclonic flow in the top layer, which is slower than the flow of the eddy directly underneath it, i.e., a subsurface velocity maximum (Figure 13b).

\subsection{Could the Causes of Flooding be Different Between the Model and Observations?}

[64] The modeled eddy is similar to the eddy as observed in Baird et al. [2010]. There are some differences between the model and observations, which will be explored because they could be an indication of (or lead to) different processes within the eddy.

[65] In the model the eddy separates from the EAC on model day 27 (around the 2 November) whereas the observed eddy does not separate for another 31 days (3 December). In addition, the submergence in the observations started earlier and was more extensive (approximately $50 \mathrm{~m}$ ). This could also be an indication of different processes driving the submergence and will directly affect the volume of EAC waters entering the eddy. Less water entering the eddy is most likely the cause of the shallower submerged depth in the model as compared to the observations. While a direct measure of other effects that these differences could have on the results presented here cannot be obtained, there are some indirect measures, which can show how robust the conclusions of this paper are.

[66] One of the main results of this paper is that vorticity intensification drives some of the overwashing. Sea-level height changes are a good indication of changes in vorticity and both the observed and modeled sea-level height changes evolve similarly. In particular, the sea level height changes in the observations and model from days 17 to 26 are in good agreement (Figure 2g). This is when the vorticity intensification occurs in the model so it is likely that it is also occurring in the observed eddy.

[67] The cyclonic vorticity which appeared as a barrier between the EAC and the eddy could not be resolved in the geostrophic currents derived from altimetry. Because the flooding in the observed WCE preceded that of the modeled WCE, it is possible that this barrier might not exist in the observed eddy. The observed eddy, however, did not immediately start sinking below the EAC (despite the EAC having a greater buoyancy from the start) so a barrier to the submergence does exist.

\section{Summary}

[68] For the first time, we have successfully modeled a WCE observed off southeast Australia that was encircled and then overwashed by the EAC before separation. This simulation provided the ideal opportunity to investigate the spatial and temporal evolution of an overwashing WCE in a western boundary current. We have identified two distinct stages in the process, the encircling of the eddy (days 1-18) and the overwashing of the eddy (days 19-27).
[69] During encircling the eddy was a small, typical downwelling eddy. The EAC circled this eddy and, while both the EAC and the eddy had an anticyclonic vorticity, a cyclonic barrier formed between them. The EAC encircled the eddy and this cyclonic water was ejected from the eddy to the north. This pulled in high-vorticity waters from the EAC, which then spun up the eddy.

[70] During overwashing the EAC retroflection formed a closed loop around the eddy, becoming part of the eddy. A shallow surface current moved across the original eddy, mixing with the original eddy waters. The mixed overwashing current submerged the original eddy, which resulted in a two-layered system, the bottom consisting of the original eddy water and the top consisting of EAC waters. This two-layered system had a subsurface maximum velocity at the interface of the two layers. The vertical circulation structure changes during the overwashing process whereby the eddy was submerged at the core and then pushed up at the edges.

[71] Acknowledgments. Thanks to the developers and contributors to ROMS. Thanks to the scientists and crew of the Southern Surveyor cruise (SS200810). The Argo float data were collected and made available by the International Argo Project and the national programs that contribute to it. Argo is a pilot program of the Global Ocean Observing System, and is supported by Argo Australia. Argo Australia is a facility of the Integrated Marine Observing System (IMOS). SST data and SynTS products were provided by The Commonwealth Scientific and Industrial Research Organisation Marine and Atmospheric Research. The wind speed data provided by NOAA Satellite and Information Service, National Environmental Satellite, Data and Information Services from their website at http://www.ncdc.noaa. gov/oa/rsad/air-sea/seawinds.html. The other products used in the atmospheric forcing came from NCEP Re-analysis products, provided by the NOAA/Office of Oceanic and Atmospheric Research (OAR)/Earth System Research Laboratory (ESRL) Physical Sciences Division (PSD), Boulder, Colorado, USA from their web site at http://www.esrl.noaa.gov/psd. We are also grateful to the three anonymous reviewers whose contribution significantly improved this manuscript.

\section{References}

Baird, M., I. Suthers, D. Griffin, B. Hollings, C. Pattiaratchi, J. Everett, M. Roughan, K. Oubelkheir, and M. Doblin (2010), The effect of surface flooding on the physical-biogeochemical dynamics of a warm core eddy off southeast Australia, Deep Sea Res. Part II: Topical Studies in Oceanography, 58, 592-605.

Bakun, A. (2006), Fronts and eddies as key structures in the habitat of marine fish larvae: opportunity, adaptive response and competitive advantage, $\mathrm{Sci}$. Mar., 70(S2), 105-122.

Bowen, M., J. Wilkin, and W. Emery (2005), Variability and forcing of the East Australian Current, J. Geophys. Res., 110(C3), C03019, doi:10.1029/ 2004JC002533

Capet, X., J. McWilliams, M. Molemaker, and A. Shchepetkin (2008), Mesoscale to submesoscale transition in the California Current system. Part II: Frontal processes, J. Phys. Oceanogr, 38, 44-64.

Chapman, D. (1985), Numerical treatment of cross-shelf open boundaries in a barotropic coastal ocean model, J. Phys. Oceanogr, 15(8), 1060-1075.

Chapman, R., and D. Nof (1988), The sinking of warm-core rings, J. Phys. Oceanogr, 18, 565-583.

Cresswell, G. (1983), Physical evolution of Tasman Sea eddy J, Mar. Freshwater Res., 34, 495-513.

Deng, X., D. Griffin, K. Ridgway, J. Church, W. Featherstone, N. White, and M. Cahill (2011), Satellite Altimetry for Geodetic, Oceanographic, and Climate Studies in the Australian Region. In: Vignudelli, S., Kostianoy, A. G., Cipollini, P., Benveniste, J. (Eds.), Coastal Altimetry. Springer Berlin Heidelberg, pp. 473-508.

Didden, N., and F. Schott (1993), Eddies in the North Brazil Current retroflection region observed by GEOSAT altimetry, J. Geophys. Res. [Oceans], 98(C11), 20121-20131, doi:10.1029/93JC01184.

Dietze, H., R. Matear, and T. Moore (2009), Nutrient supply to anticyclonic meso-scale eddies off western Australia estimated with artificial tracers released in a circulation model, Deep-Sea Res., Part I, 56, 1440-1448. 


\section{MACDONALD ET AL.: OVERWASHING A WARM-CORE EDDY}

Duncan, C. (1968), An eddy in the subtropical convergence southwest of South Africa, J. Geophys. Res., 73(2), 531-534, doi:10.1029/ JB073i002p00531.

Everett, J., M. Baird, P. Oke, and I. Suthers (2012), An avenue of eddies: Quantifying the biophysical properties of mesoscale eddies in the Tasman Sea, Geophys. Res. Lett, 39(16), L16608, doi:10.1029/2012GL053091.

Fairall, C., et al. (1996), Bulk parameterization of air-sea fluxes for tropical ocean-global atmosphere coupled-ocean atmosphere response experiment, J. Geophys. Res, 101(C2), 3747-3764, doi:10.1029/JC090iC05p08917.

Flather, R. (1976), A tidal model of the northwest European continental shelf, Mem. Soc. R. Sci. Liege, 6(10), 141-164.

Flierl, G., and R. Mied (1985), Frictionally induced circulations and spin down of a warm-core ring, J. Geophys. Res., 90(C5), 8917-8927.

Godfrey, J., G. Cresswell, T. Golding, A. Pearce, and R. Boyd (1980), The separation of the East Australian Current, J. Phys. Oceanogr., 10(3), 430-440.

Hamon, B. (1965), The East Australian Current, 1960-1964. In: Deep-Sea Res. Oceanogr. Abstr. Vol. 12. Elsevier, pp. 899-921.

Hitchcock, G. L., C. Langdon, and T. Smayda (1985), Seasonal variations in the phytoplankton biomass and productivity of a warm-core Gulf Stream ring, Deep-Sea Res., Part A, 32(11), 1287-1300.

Jeffrey, S., and G. Hallegraeff (1987), Phytoplankton pigments, species and light climate in a complex warm-core eddy of the East Australian Current, Deep-Sea Res., Part A, 34(5-6), 649-673.

Kahru, M., B. Mitchell, S. Gille, C. Hewes, and O. Holm-Hansen (2007), Eddies enhance biological production in the Weddell-Scotia Confluence of the Southern Ocean, Geophys. Res. Lett, 34, L14603, doi:10.1029/ 2007 GL030430.

Kalnay, E., et al. (1996), The NCEP/NCAR 40-Year Reanalysis Project, Bull. Am. Meteorol. Soc., 77(3), 437-471.

Mata, M., S. Wijffels, J. Church, and M. Tomczak (2006), Eddy shedding and energy conversions in the East Australian Current, J. Geophys. Res., [Oceans] 111, doi:10.1029/2006JC003592.

McGillicuddy, D. J., et al. (2007), Eddy/wind interactions stimulate extraordinary mid-ocean plankton blooms, Science, 316(5827), 1021-1026.

Mellor, G., T. Ezer, and L. Oey (1994), The pressure gradient conundrum of sigma coordinate ocean models, J. Atmos. Ocean. Tech., 11, 1126-1134.

Mellor, G., and T. Yamada (1982), Development of a turbulence closure model for geophysical fluid problems, Rev. Geophys. Space Phys., 20(4), 851-875, doi:10.1029/RG020i004p00851.

Nelson, D., J. McCarthy, T. Joyce, and H. Ducklow (1989), Enhanced near-surface nutrient availability and new production resulting from the frictional decay of a Gulf Stream warm-core ring, Deep-Sea Res., Part A, 36(5), 705-714.

Nilsson, C., and G. Cresswell (1980), The formation and evolution of East Australian current warm-core eddies, Prog. Oceanogr., 9(3), 133-183. [http://www.sciencedirect.com/science/article/pii/007966 1180900087].
Nof, D., and W. Dewar (1994), Alignment of lenses: laboratory and numerical experiments, Deep-Sea Res., Part I, 41(8), 1207-1229.

Oort, A. (1964), Computations of the eddy heat and density transports across the Gulf Stream, Tellus, 16(1), 55-63.

Parker, C. E. (1971), Gulf Stream rings in the Sargasso Sea, Deep-Sea Res. Oceanogr. Abstr., 18(10), 981-993.

Ridgway, K., and J. Godfrey (1997), Seasonal cycle of the East Australian Current, J. Geophys. Res. [Oceans], 102(C10), 22,921-22,936, doi:10.1029/ 2007JC004664.

Ridgway, K., R. Coleman, R. Bailey, and P. Sutton (2008), Decadal variability of East Australian Current transport inferred from repeated highdensity XBT transects, a CTD survey and satellite altimetry, J. Geophys. Res., 113(C08039), doi:10.1029/97JC00227.

Rossby, T. (1987), On the energetics of the Gulf Stream at 73 W, J. Mar. Res., 45(1), 59-82.

Roughan, M., P. Oke, and J. Middleton (2003), A modeling study of the climatological current field and the trajectories of upwelled particles in the East Australian Current, J. Phys. Oceanogr., 33(12), 2551-2564.

Roughan, M., H. S. Macdonald, M. E. Baird, and T. M. Glasby (2011), Modelling coastal connectivity in a western boundary current: Seasonal and inter-annual variability, Deep-Sea Res., Part II, 58(5), 628-644.

Shchepetkin, A., and J. McWilliams (2003), A method for computing horizontal pressure-gradient force in an oceanic model with a nonaligned vertical coordinate, J. Geophys. Res, 108(C3), 3090, doi:10.1029/ 2001JC001047.

Shchepetkin, A., and J. McWilliams (2005), The regional oceanic modeling system (ROMS): a split-explicit, free-surface, topography-following-coordinate oceanic model, Ocean Modelling, 9(4), 347-404.

Sikiric, M., I. Janekovic, and M. Kuzmic (2009), A new approach to bathymetry smoothing in sigma-coordinate ocean models, Ocean Modelling, 29(2), 128-136.

Tranter, D., G. Leech, and D. Vaudrey (1982), Biological significance of surface flooding in warm-core ocean eddies, Nature, 297, 572-574.

Tranter, D., R. Parker, and G. Cresswell (1980), Are warm-core eddies unproductive? Nature, 284, 540-542.

Wilkin, J., and W. Zhang (2007), Modes of mesoscale sea surface height and temperature variability in the East Australian Current, J. Geophys. Res., 112(C01013), doi:10.1029/2006JC003590.

Yang, Y., C.-T. Liu, J.-H. Hu, and M. Koga (1999), Taiwan Current (Kuroshio) and impinging eddies, J. Oceanogr., 55, 609-617.

Yaochu, Y., and S. Jilan (1988), The calculation of Kuroshio current structure in the East China Sea-early summer 1986, Prog. Oceanogr., 21(3-4), 343-361.

Zhang, H., R. Reynolds, and J. Bates (2006), Blended and Gridded High Resolution Global Sea Surface Wind Speed and Climatology from Multiple Satellites: 1987- Present. American Meteorological Society 2006 Annual Meeting, Paper \#P2.23, Atlanta, GA 87 (36). 